\title{
Influence of Heirloom Tomato Polyphenol Extracts on Expression of Inflammation Genes in Bovine
}

\author{
Kwaku Gyenai, Nona Mikiashvili, Hamid Ismail and Mulumebet Worku \\ Department of Animal Sciences, North Carolina Agricultural and Technical State University, \\ B.C. Webb hall, 1601 East Market Street, Greensboro NC 27411, Greensboro
}

Received 2012-07-01, Revised 2012-08-21; Accepted 2012-08-25

\begin{abstract}
The effect of tomato on diseases of economic importance continues to be of broad interest. To evaluate these relationships, the effect of crude extracts of Cherokee purple tomato on pro-inflammatory genes and cytokines were evaluated. Neutrophils from three Holstein Fresian cows were treated with Phosphate Buffered Saline (PBS) or E. coli O111-B4 Lipopolysaccharide (LPS). Treated cells were exposed to different concentrations of polyphenol extracts of fresh and heated Cherokee purple. Transcription of Cyclooxygenase-2 (Cox-2) and Tumor Necrosis Factor-alpha (TNF- $\alpha$ ) was detected using real time PCR. Secretion of cytokines was evaluated using specific Enzyme-Linked Immunosorbent Assay (ELISA)'s for three pro-inflammatory genes. Transcription of Cox-2 and TNF- $\alpha$ in bovine neutrophils were found. No significant treatment effect of tomato polyphenols was found in the LPS treated neutrophils. TNF- $\alpha$ and Cox- 2 expression in bovine neutrophils were modulated by polyphenol treatment. Variable concentration of polyphenol extracts had no effect on Cox-2 transcription. Gene expression analysis of TNF- $\alpha$ and Cox -2 mRNA showed significantly decreased transcription of Cox-2 in neutrophils exposed to polyphenol extracts $(\mathrm{p}<0.0326)$. Polyphenol exposure did not have an influence on induction of Cox-2 by LPS. Treatment with polyphenols decreased transcription of TNF- $\alpha$ at the level of $200 \mathrm{ng}$ $\mathrm{mL}^{-1}(\mathrm{p}<0.05)$. Fresh or heated polyphenol did not influence transcription of TNF- $\alpha$. Significant variation was observed among cows in transcription of TNF- $\alpha(p<0.05)$. No significant treatment effect was observed for translation in Cox-2, TNF- $\alpha$ and GCSF exposed to fresh or heated polyphenol extracts. Relative secretion of the antiviral pro-inflammatory cytokine IFNr was increased compared to the control in samples exposed to heated tomato polyphenol extracts $(\mathrm{p}<0.05)$. Results showed that tomato polyphenols modulate expression of proinflammatory genes in bovine neutrophils and may provide avenues to boost innate immunity. To our knowledge, this is the first study to discuss the role Cherokee purple polyphenol extracts plays in innate immunity.
\end{abstract}

Keywords: Bovine, Tomato Polyphenol, Transcription, Enzyme-Linked Immunosorbent Assay (ELISA), Phosphate Buffered Saline (PBS)

\section{INTRODUCTION}

Globally, tomatoes (Solanum lycopersicum L.) are the second most important vegetable crop (Lucier et al., 2008). Tomato by-products, cull tomatoes, tomato leaves and tomato seed cake are used as animal feed (Heuze et al., 2011; Hoover and Denison, 1957). In animal feeds, tomatoes have been discussed to have nutritive value (Ventura et al., 2009). In humans, it reduces chronic diseases through antioxidant, antithrombotic and antiinflammatory actions (Ellinger et al., 2006; Burton-
Freeman and Reimers, 2010). Medicinal properties of tomato include its use as antibiotics, anticancer, anticholesterol, anti-inflammatory, antinociceptives and antipyretic was reported (Milner et al., 2011). However, studies on the effect of tomato on animal health remain limited.

Genetics, environment, cultural practices and post harvest handling and processing (Shen et al., 2007) can impact the phyto-chemical composition of tomatoes. Preharvest approaches at improving tomato nutritional quality and health benefits attempt to harness natural

Corresponding Author: Kwaku Gyenai, Department of Animal Sciences, North Carolina Agricultural and Technical State University, B.C. Webb hall, 1601 East Market Street, Greensboro NC 27411, Greensboro 
genetic variation (Melendez-Martinez et al., 2010). Heirloom (open pollinated) varieties offer producers avenues for diversification of products. Consumer interest in heirloom and specialty tomato varieties is growing for their taste, unique shapes and colors. Cherokee purple is a member of the "black" color group of tomatoes popular for its flavor and it's naturally rich anthocyannins. Genetically modified purple tomatoes are enriched with anthocyanins and have been shown to fight cancer in mice (Butelli et al., 2008).

The effect of post harvest technologies when the plants are processed and/or cooked at optimal conditions for bioavailability of bioactive compounds require further study (Gahler et al., 2003; Shen et al., 2007; Basu and Imrhan, 2007; Rafi et al., 2007). Post harvest heat treatment of tomatoes affects fruit ripening and decay (Falik, 1993). Shen et al. (2007) reported increases in the phenolic content of big and small tomatoes by blanching and heating. Tomato phenolics showed fair antioxidant activity and synergistically promoted the antioxidation of tomato carotenoids and may play an important role in the chemoprevention of cancer (Shen et al., 2007).

Inflammatory conditions are associated with oxidative stress and recruitment of inflammatory cells and compounds (Sautebin, 2000), Bacterial Lipopolysaccharide (LPS) from the cell wall of gram negative organisms such as environmental $E$. coli is able to induce an inflammatory response. Endotoxin activates expression of pro-inflammatory genes through the binding of the LPS-binding protein to CD14, a membrane glycophosphatidylinositol anchored protein (Lahti et al., 2000) and Toll-like receptor-4 (Silva et al., 2008; Worku and Morris, 2009) on neutrophils and macrophages. Leukocytes such as the neutrophil are recruited from blood to remove bacteria (Black, 2000). Activated leuckocytes phagocytose bacteria produce cytokines such as: TNF- $\alpha$, interferon, interleukin's and Granulocyte-Colony Stimulating factor (Black, 2000; Grimble, 1990). Dietary factors play a significant role in the initiation of innate immunity and cytokine secretion. Tomato derived compounds prevent degenerative disease by lessening the production of inflammatory mediators such as TNF- $\alpha$ (Riso et al., 2006) and Cox-2 catalyzes prostaglandin (Shen et al., 2007; Rafi et al., 2007; Liang et al., 1999). Neutrophil gene expression and the response to modulation with polyphenols has been described as a therapeutic approach for the treatment of chronic diseases and Cox-2 is an important target for polyphenolic agents derived from the diet (Plummer et al., 2001).

Neutrophils are first responders in the cows' defense against infection with $E$. coli. Effective elimination of the pathogen by neutrophils is important for the resolution of infection and the outcome of diseases such as E. coli mastitis (Burvenich et al., 2006; Worku and Morris, 2009). Defects in neutrophil recruitment to the site of infection (Schwalm et al., 1976; Nagahata, 2004) or reduced neutrophil functioning (Roth et al., 1981; Tkalcevic et al., 2000) or both are associated with impaired host clearance of bacteria.

In light of the need to characterize heirloom tomatoes and the potential benefits of tomatoes for health; the objectives of this study were to evaluate the impact of post harvest heat treatment and extraction on polyphenol concentration of CherokeePurple tomatoes and its effect on expression of select pro-inflammatory genes in isolated bovine blood neutrophils and changes in cytokine levels.

\section{MATERIALS AND METHODS}

\subsection{Animals and Blood Sampling}

Three clinically healthy Holstein Friesian cows, pasturing at the North Carolina Agricultural and Technical State University dairy farm were used. The protocol was approved by the university animal care and use committee. The cows were clinically free of infections and not under any medical or feeding treatment during the period of this study.

\subsection{Neutrophil Isolation}

Fifteen milliliters of blood was collected from the jugular vein of cows and placed into vacutainer tubes containing anticoagulant. Neutrophils were isolated from blood samples by differential centrifugation and hypotonic lyses of red blood cells using the modified Carlson and Kaneko (1973) method. All reagents used in this study were prepared in Lipopolysaccharide (LPS) free reagent grade water.

\subsection{Neutrophil Purity and Viability}

Differential cell counts were conducted on Sure Stain Wright smears prepared from the cell suspension using an Olympus B X40 microscope. Briefly; a thin blood smear was placed was spread on a micro slide. The slide was left to air dry at room temperature then stained with Sure Stain Wright CS-432 solution according to the manufactures Instructions (Fisher Scientific Inc. Pittsburgh, PA), slides were dipped in Wright stain for 10 seconds then in deionized water for 15 seconds and finally rinsed by dipping in fresh deionized water for 10 seconds. The slides were left to dry at room temperature.

The purity of cells was expressed as a percentage (>90\%). Qualitative measure of cell viability in peripheral blood of neutrophils was evaluated in this preliminary study. Neutrophil viability was assessed 
using the Trypan blue dye exclusion method by counting 100 cells in duplicate and determining the number of viable cells from isolated neutrophils using an Olympus B X40 microscope (Celis, 2006). The trypan blue exclusion test has been discussed to be rapid in assessing cell viability in response to environmental insults. It is based on the ability of viable cells to be impermeable to try pan blue, naphthalene black, erythrosine and other dyes (Celis, 2006).

\subsection{Tomato Treatment and Preparation of Crude Polyphenol Extract}

Heirloom tomatoes (Cherokee purple), were purchased from a farm in Guilford County North Carolina. Both fresh and heated tomatoes were used in this study. To prepare heated tomato extracts, Cherokee purple tomatoes were cleaned blanched in $85^{\circ} \mathrm{C}$ water for $5 \mathrm{~min}$, followed by boiling in water for $30 \mathrm{~min}$. Both fresh and blanched tomatoes were immediately used for extraction of polypheonols. Tomato samples (about 150 g) were extracted with $80 \%$ aqueous acetone, methanol or acetonitril $(1: 1[\mathrm{w} / \mathrm{v}])$ separately in a lab Warring blender for $1 \mathrm{~min}$ at room temperature, incubated $5 \mathrm{~min}$, RT and filtered through Whatman paper under vacuum. The filtrate was evaporated by a rotary evaporator under vacuum conditions $\left(30^{\circ} \mathrm{C}, 33.1 \mathrm{mbar}\right.$ pressure $)$. The dried residual material was crude polyphenol extract, which was frozen at $-20^{\circ} \mathrm{C}$ before analysis. For cell exposure experiment polyphenol pellets were dissolved in Phosphate Buffered Saline (PBS).

\subsection{Soxhlet Extraction of Tomato}

The residual material, crude phenolic extract was extracted using the Soxhlet method. The soxhlet method consisted of $15 \mathrm{~g}$ crude phenolic extract placed inside a glass thimble and loaded into the main chamber of the soxhlet apparatus, composed by an extracting tube, a glass balloon and a condenser. The total extracting time was $3 \mathrm{~h}$ with methanol, acetone or hexane separately to evaluate which solvent yielded the highest phenolic levels. The extracted solutions using each organic solvent were pooled and evaporated to oil and waxy like substance at $40^{\circ} \mathrm{C}$ by rotary evaporation under reduced pressure. Infrared spectroscopy was used to identify the organic (Phenolics) and organometallic molecules.

\subsection{Estimation of Polyphenol Contents}

Total phenolic contents were determined using FolinCiocalteu phenol reagent (Merck Whitehouse Station, NJ) (Shen et al., 2007). A total of $50 \mu \mathrm{L}$ HT was diluted with water to $2 \mathrm{~mL}$ in a $10-\mathrm{mL}$ measuring flask. FolinCiocalteu phenol reagent $(1 \mathrm{~mL})$ was added and shaken vigorously in a flask. Immediately, $5 \mathrm{~mL}$ of (20\%) or 2.4 mol $\mathrm{L}^{-1}$ sodium carbonate solution was pipetted, followed by thorough shaking. After $20 \mathrm{~min}$, the absorbance of the mixture was read at $735 \mathrm{~nm}$ using a spectrophotometer, without background measurements and using gallic acid (Sigma- Aldrich, St. Louis, MO) as a standard. Samples were centrifuged if necessary due to the potential of precipitate formation. Total phenolic contents were expressed as micrograms of gallic acid equivalent per gram of fresh weight.

\subsection{Treatment of Neutrophils with Tomato Extract and LPS}

Isolated neutrophils $\left(10^{7}\right.$ cells $\left.\mathrm{mL}^{-1}\right)$ in PBS were exposed to two different concentrations of tomato polypenol extract (200 and $400 \mu \mathrm{g}$ ), for $10 \mathrm{~min}$. Cells were treated with target $E$. coli O111-B4 LPS at a concentration of $100 \mathrm{ng} \mathrm{mL}^{-1}$ for $30 \mathrm{~min}$. The cells were incubated at $37^{\circ} \mathrm{C}$ in the presence of $5 \% \mathrm{CO}_{2}$ and $95 \%$ humidity for $30 \mathrm{~min}$. At the end of the incubation period cells were spun down at $700 \mathrm{~g}$ for $5 \mathrm{~min}$. Supernatants were collected and stored $-7^{\circ} \mathrm{C}$ for further use. Cell pellets were used for total RNA isolation using Trireagent (Molecular Research Center, Inc., USA).

\subsection{Isolation of RNA}

Total RNA, was isolated using Tri-reagent (Molecular Research Center, Inc. Cincinnati, OH). The Quality and Quantity of the RNA was measured with the nanodrop spectrophotometer $(260 / 280 \mathrm{~nm})$.

\subsection{Real Time PCR}

Reverse transcriptase PCR was performed using an Oligo (dT) primer. Quantification one step RT PCR was performed in the Smart Cycler (Cepheid) in a $25 \mu \mathrm{L}$ reaction with the intercalating dye-Syber Green using gene specific primers according to Schmitz et al. (2004) (Table 1). The method used a relative quantification with normalization to a reference gene (GAPDH) to calculate expression levels in target samples. The expression levels of reference gene were taken into account. The relative expression of selected genes, with GAPDH as the reference gene, was determined using the $2^{-\Delta \Delta C t}$ method (Pfaffl, 2001). Amplified samples were run on $2.5 \%$ agarose gel and visualized after staining with Ethidium bromide to determine amplicon size.

\subsection{Cytokine Measurement}

Supernatants collected from neutrophil treatment preparations were used to evaluate the concentration of inflammatory cytokines. The concentration of TNF- $\alpha$, IFNr and G-CSF were measured using an inflammation 
array elisa kit according to the manufacturer's protocol (Signosis, Sunnyvale, CA).

The activation of Cox-2 was detected using a commercially available enzyme immunoassay kit to measure Prostagladin $(\mathrm{PG})_{\mathrm{E}-2}$ release in triplicate according to the manufacturer's suggested protocol (Cayman Chemical, An Arbour, MI). Briefly, $\mathrm{PG}_{\mathrm{E}-2}$ levels were measured in supernatants and absorbance read using spectrophotometer at $450 \mathrm{~nm}$ within $30 \mathrm{~min}$. Prostagladin $(\mathrm{PG})_{\mathrm{E}-2}$ levels were then calculated and data used for statistical analysis using the manufacturer's analysis software (Cayman Chemical, An Arbour, MI).

Statistical analysis: Statistical analysis was conducted using the statistical analysis software SAS (SAS Institute Inc., Cary, NC). Anova was performed to evaluate differences if any among and between secreted cytokines, prostaglandin and RNA transcripts of treated and control neutrophil samples $p<0.05$. The Dunnett's ttest was also carried out to evaluate differences between and among means.

\section{RESULTS}

This study evaluated antioxidant content and antiinflammatory effects of Cherokee Purple tomatoes. Results of crude polyphenolic extraction using three different organic solvents showed higher $(\mathrm{p}<0.05)$ total polyphenolics for acetone extraction, $7.7 \mathrm{mg} \mathrm{g}^{-1}$ for fresh tomato sample (Table 2). For heated tomato samples, the extract showed significantly increased levels, using acetone, however, not different from acentonitrile extraction (Table 2). Comparison of fresh versus heated crude polyphenol extracts showed one to two-fold increases for fresh extracts using acetone (Table 2). Results of neutophils exposed to different concentrations of fresh and heated polyphenol extracts are presented in (Table 3). No differences were observed between control and fresh polyphenol samples at differenct concentrations except for $200 \mu \mathrm{g} / \mathrm{mL}$ where viability was reduced. Similar observation was made for heated control samples however, did not differ from concentrations at 10, 200, 400 and $600 \mu \mathrm{g} / \mathrm{mL}$ (Table 3). Analysis of phenolics in all the extracts using fourier transform infrared analysis showed significantly increased phenolic peaks for acetone extraction in heated samples as compared with others (Fig. 1). Based on the observation of high phenolics in acetone extracted tomato, total phenolic levels were evaluated on fresh and heated samples. Results showed an inverse relation where, fresh tomato had increased total phenolic levels as compared with that of heated tomato extracts (Fig. 2).

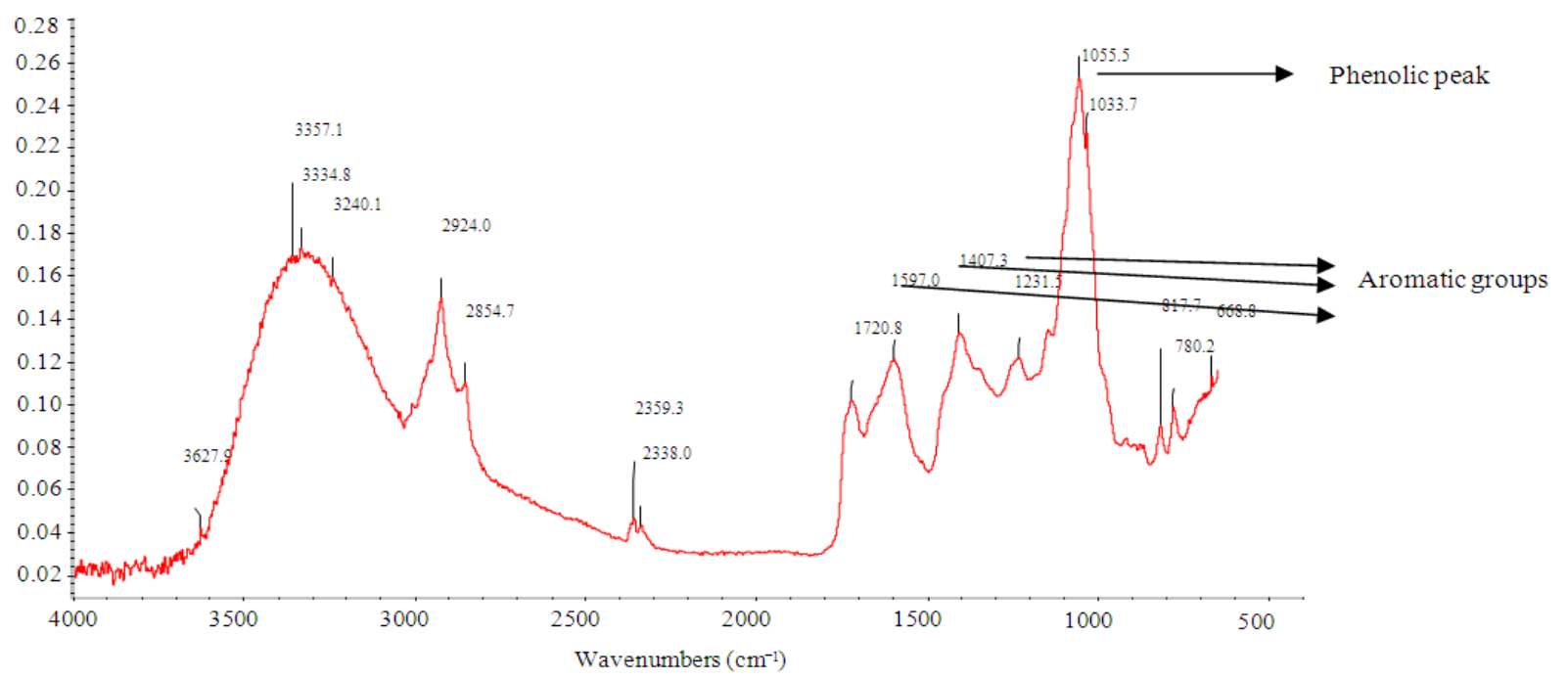

Fig. 1. Phenolic levels in Cherokee purple tomato extracted using methanol

Table 1. Primer sequences used for real time PCR and cycling conditions of all assays

\begin{tabular}{|c|c|c|c|c|c|c|c|c|c|}
\hline \multirow[b]{2}{*}{ Primer } & \multirow[b]{2}{*}{ Sequence } & \multirow{2}{*}{$\begin{array}{l}\text { Length } \\
\text { (bp) }\end{array}$} & \multirow[b]{2}{*}{ Author } & \multicolumn{2}{|c|}{ Denaturation } & \multicolumn{2}{|c|}{ Annealing } & \multicolumn{2}{|c|}{ Elongation } \\
\hline & & & & ${ }^{\circ} \mathrm{C}$ & $\mathrm{s}$ & ${ }^{\circ} \mathrm{C}$ & $\mathrm{s}$ & ${ }^{\circ} \mathrm{C}$ & $\mathrm{s}$ \\
\hline $\mathrm{COX}-2$ & $\begin{array}{l}\text { For: 5'- TCT TCC TCC TGT GCC TGA T - 3' } \\
\text { Rev: 5'- CTG AGT ATC TTT GAC TGT GG -3, }\end{array}$ & 358 & $\begin{array}{l}\text { Schmitz } \\
\text { et al. (2004) }\end{array}$ & 95 & 30 & 62 & 60 & 72 & 30 \\
\hline TNF- $\alpha$ & $\begin{array}{l}\text { For: 5'-TAA CAA GCC GGT AGC CCA CG -3' } \\
\text { Rev: 5'-GCA AGG GCT CTT GAT GGC AGA -3' }\end{array}$ & 277 & $\begin{array}{l}\text { Schmitz et } \\
\text { al. }(2004)\end{array}$ & 95 & 30 & 62 & 60 & 72 & 30 \\
\hline
\end{tabular}


Table 2. Crude polyphenols extraction using various organic solvents

\begin{tabular}{lll}
\hline Solutions & Total polyphenols in fresh tomato $(\mathrm{mg} / \mathrm{g})$ & Total polyphenols in heated tomatos (mg/g) \\
\hline Acetonitrile & $3.78 \pm 1.14^{\mathrm{b}}$ & $5.54 \pm 1.67^{\mathrm{a}}$ \\
Methanol & $4.05 \pm 1.24^{\mathrm{a}}$ & $3.2 \pm 1.06^{\mathrm{ab}}$ \\
Acetone & $7.7 \pm 1.6^{\mathrm{a}}$ & $5.8 \pm 1.14^{\mathrm{b}}$ \\
\hline Results represent averages of crude tomato polyphenol extracted using different organic solvents expressed as mean \pm SE; ${ }^{\text {ab }}$ Averages in the same row
\end{tabular}
with same superscript are statistically not significant $* \mathrm{p}<0.05$

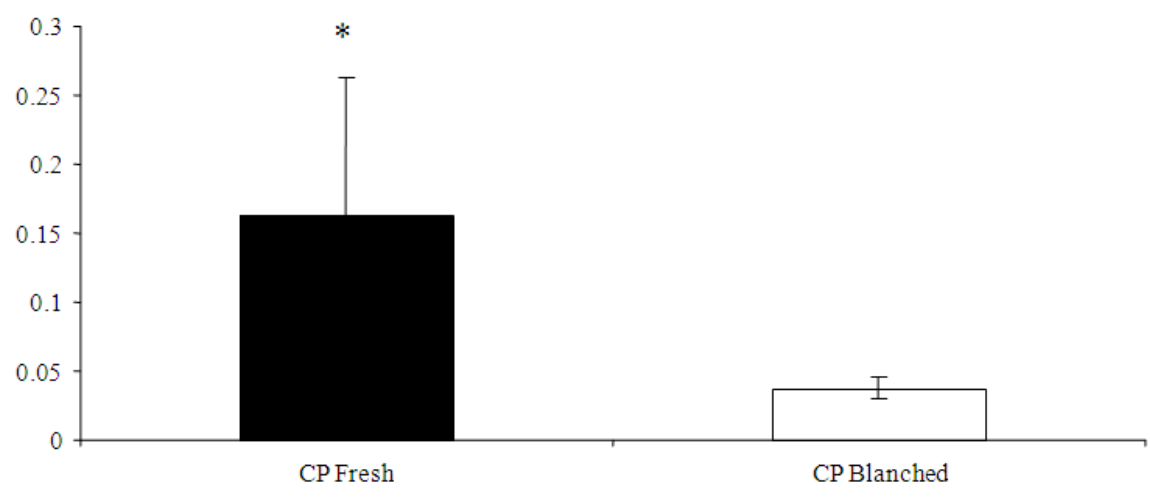

Fig. 2. Total phenolic content of fresh Vs. blanched Cherokee Purple (CP) tomato $* p<0.05$

Table 3. Neutrophils viability levels after exposure to different concentration of heirloom tomato

\begin{tabular}{lll}
\hline Polyphenols $(\mu \mathrm{g} / \mathrm{mL})$ & Fresh Tomato extract cells viability $(\%)$ & Heated Tomato extract cells viability $(\%)$ \\
\hline Control & $93.0 \pm 6.8^{\mathrm{a}}$ & $93.4 \pm 5.2^{\mathrm{a}}$ \\
10.0 & $91.0 \pm 15.4^{\mathrm{a}}$ & $89.7 \pm 12.5^{\mathrm{a}}$ \\
20.0 & $89.7 \pm 28.4^{\mathrm{a}}$ & $83.0 \pm 12.5^{\mathrm{b}}$ \\
40.0 & $87.3 \pm 21.1^{\mathrm{a}}$ & $84.7 \pm 6.0^{\mathrm{b}}$ \\
120.0 & $91.0 \pm 6.0^{\mathrm{a}}$ & $85.3 \pm 3.5^{\mathrm{b}}$ \\
200.0 & $81.0 \pm 6.0^{\mathrm{b}}$ & $88.0 \pm 16.3^{\mathrm{ab}}$ \\
400.0 & $90.0 \pm 9.2^{\mathrm{a}}$ & $92.6 \pm 12.2^{\mathrm{a}}$ \\
600.0 & $90.2 \pm 12.0^{\mathrm{a}}$ & $91.0 \pm 10.8^{\mathrm{a}}$ \\
\hline
\end{tabular}

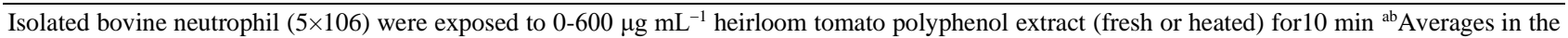
same row with same superscript are statistically not significant $* \mathrm{p}<0.05$

Table 4. RNA concentration of tomato extract exposed to normal and LPS treated neutrophils

\begin{tabular}{lll}
\hline Treatment & Fresh tomato & Heated tomato \\
\hline PBS Control & $3696.3 \pm 91.8^{\mathrm{b}}$ & $3492.0 \pm 102.2^{\mathrm{c}}$ \\
LPS & $3844.3 \pm 152.0^{\mathrm{a}}$ & $3704.1 \pm 165.0^{\mathrm{a}}$ \\
Polyphenol extract & $3489.7 \pm 249.2^{\mathrm{c}}$ & $3723.7 \pm 189.2^{\mathrm{a}}$ \\
Polyphenol extract + LPS & $3735.3 \pm 199.9^{\mathrm{ab}}$ & $3642.0 \pm 170.0^{\mathrm{ab}}$ \\
\hline
\end{tabular}

Results represent the averages of 3 animals expressed as mean \pm SE; ${ }^{\text {abc Averages in the same row with same superscript are statistically not }}$ significant $* \mathrm{p}<0.05$

To evaluate the influence of fresh and/or heated crude phenolic tomato extracts on neutrophils viability. Varying concentrations of fresh and heated tomato polyphenol extracts ranging from 10 to $600 \mu \mathrm{g}$ were exposed to neutrophil. No significant difference in cell viability between and among the different treatment groups was observed (Table 4). Results for fresh tomato group showed increased RNA concentrations for LPS treated with those treated with polyhenol extract having the lowest. For heated tomato polyphenol and LPS had highest levels respectively, however not different from each other. Further analysis was conducted to evaluate the influence of PBS, fresh tomato, LPS and fresh tomato and LPS in combination. Results showed PBS to have as much as $15 \%$ higher cell viability as compared with the other treatment groups (Fig. 3). Similar though different trend was observed for PBS. PBS and heated samples were shown to have higher cell viability respectively. The differences were by as much as 30 and $15 \%$ respectively (Fig. 3).

To examine the influence of extracts of Heirloom Tomato Polyphenols (HTP) on transcription and translation in LPS activated neutrophils, we investigated the effect of the HTP extract at two concentrations, 200 $\mu \mathrm{g}$ and $400 \mu \mathrm{g}$ of fresh and heated tomatoes on expression of Cox-2 and TNF- $\alpha$ using PBS as control (Fig. 
4 and 5). Comparison of the treatment groups showed LPS treated groups to have highest RNA concentrations in samples treated with fresh tomato with the exception of polyphenol extracts where samples incubated with extracts from heated tomatoes were significantly higher (Table 4). Cow variation was observed during transcription, potentially contributing to the variation observed.
Previous studies in our lab showed Cox-2 (Waterman and Worku, 2001) and TNF- $\alpha$ (Worku and Morisson, 2009) were expressed by bovine neutrophil and can be modulated by treatment with LPS. Levels of Cox-2 and TNF- $\alpha$ fold expression at different concentrations are shown in Fig. 4 and 5.

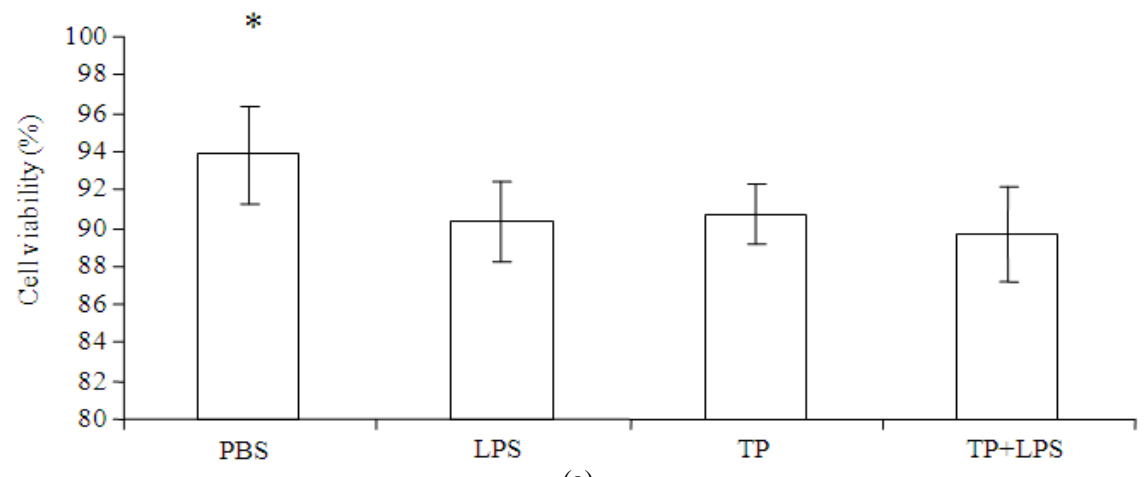

(a)

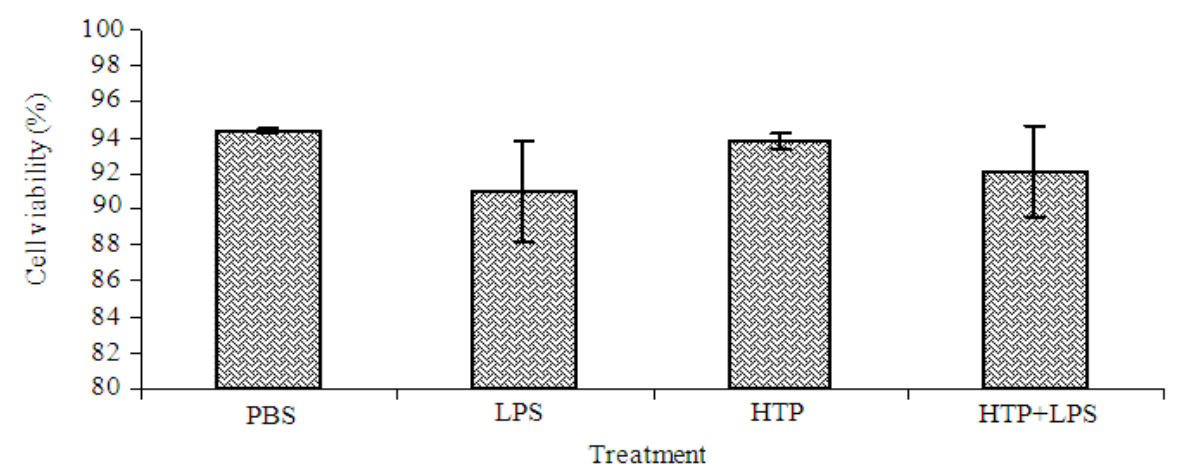

(b)

Fig. 3. Percent Viablity of Neutrophils $(5 \times 106)$ were pre-incubated with fresh (a) and heated; (b) tomato extracts, 10 min, then exposed to $100 \mathrm{ng} \mathrm{mL} \mathrm{mL}^{-1}$ LPS $30 \mathrm{~min}$. TP=tomato polyphenols; HTP=heated tomato polyphenols. *p<0.05

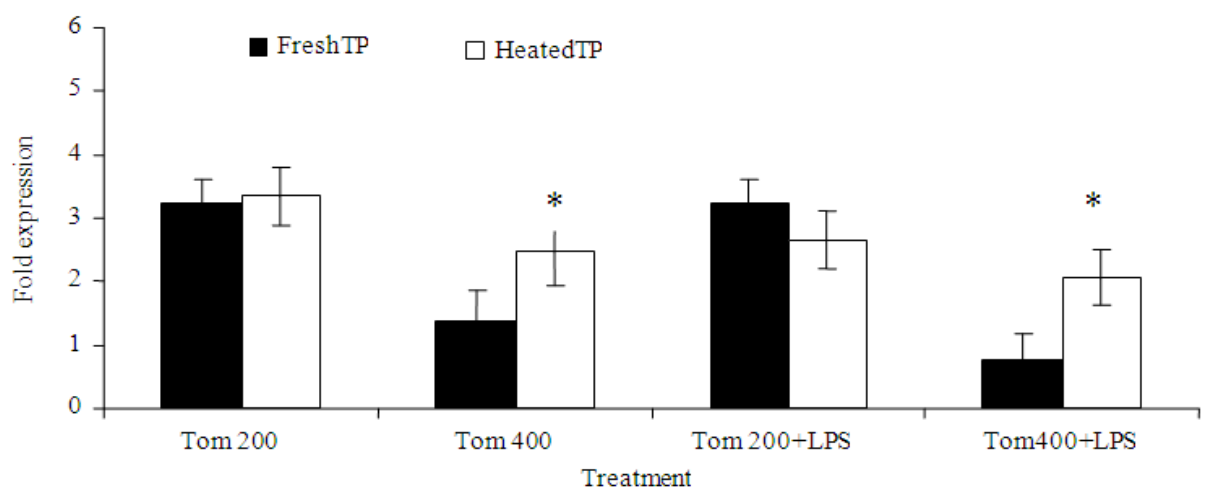

Fig. 4. Cyclooxygenase-2 (Cox-2) expression of different concentrations of fresh tomato lyphenolic (FreshTP) and heated tomato polyphenolic (HeatedTP) extracts exposed to bovine neutrophils. $* \mathrm{p}<0.05$ 
The polyphenol fraction from fresh tomatoes suppressed Cox-2 expression $(\mathrm{p}<0.05)$. Polyphenolic extracts of heated tomatoes resulted in increased suppression of Cox-2 expression compared with that of fresh tomato (Fig. 4). However, polyphenolic extracts of heated and fresh tomato did not show significant changes on TNF- $\alpha$ expression (Fig. 5). Transcription of Cox-2 was significantly decreased in neutrophils exposed to tomato extracts compared to the control $(\mathrm{p}<0.0326)$. Tomato exposure did not have an effect on induction of Cox -2 by LPS. Relative expression of Cox-2 compared to the control was higher in samples exposed to extracts from fresh tomatoes compared to extracts from heated tomatoes $(p<0.05)$. There was no effect of tomato concentration on Cox-2 transcription $(p<0.05)$.

Analysis of the influence of fresh and heated crude tomato polyphenol extracts may have, if any, on $\mathrm{s}$ showed no significant differences between fresh and heated tomato with the exception of cytokine IFNr where samples from treatment with heated extracts were increased when compared to fresh (Fig. 6). A similar trend of no significant difference was observed for that of PGE-2 measurements of neutrophils treated with heated or fresh tomatos (Fig. 7).

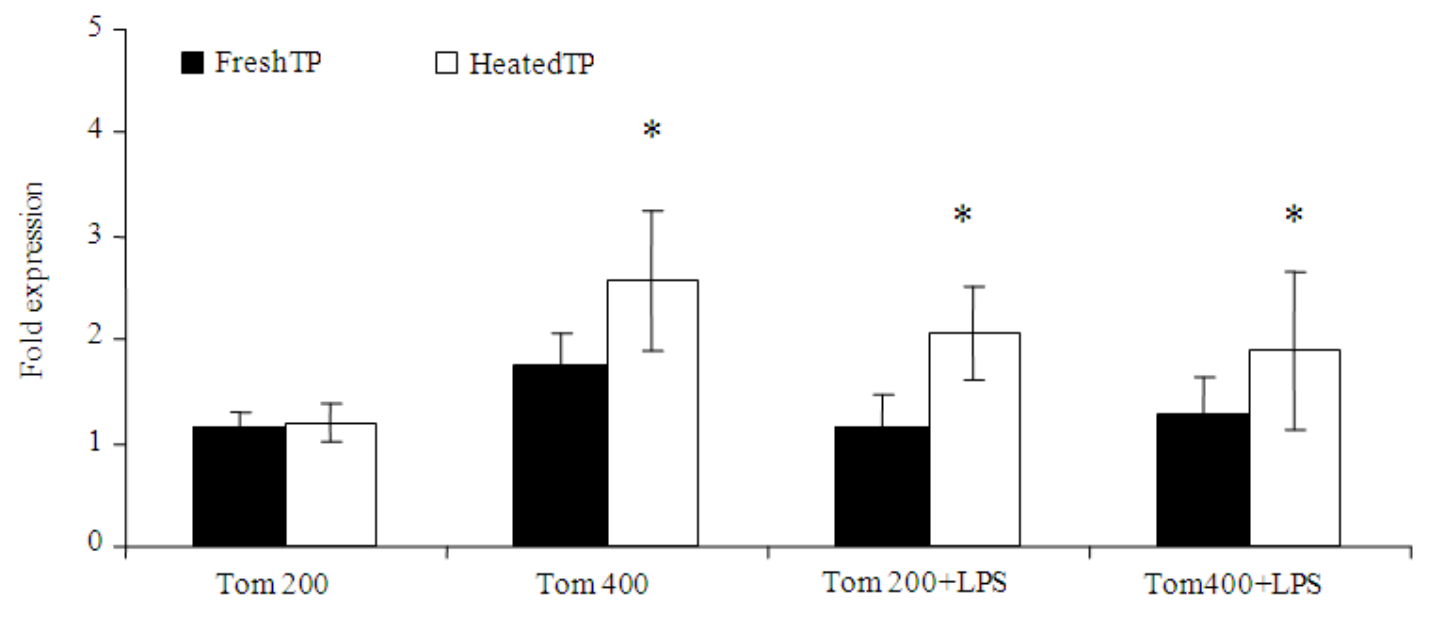

Fig. 5. Tumor Necrosis Factor-alpha (TNF- $\alpha$ ) expression of different concentrations of fresh tomato polyphenolic (FreshTP) and heated tomato polyphenolic (HeatedTP) extracts exposed to bovine neutrophils. ${ }^{*} \mathrm{p}<0.05$

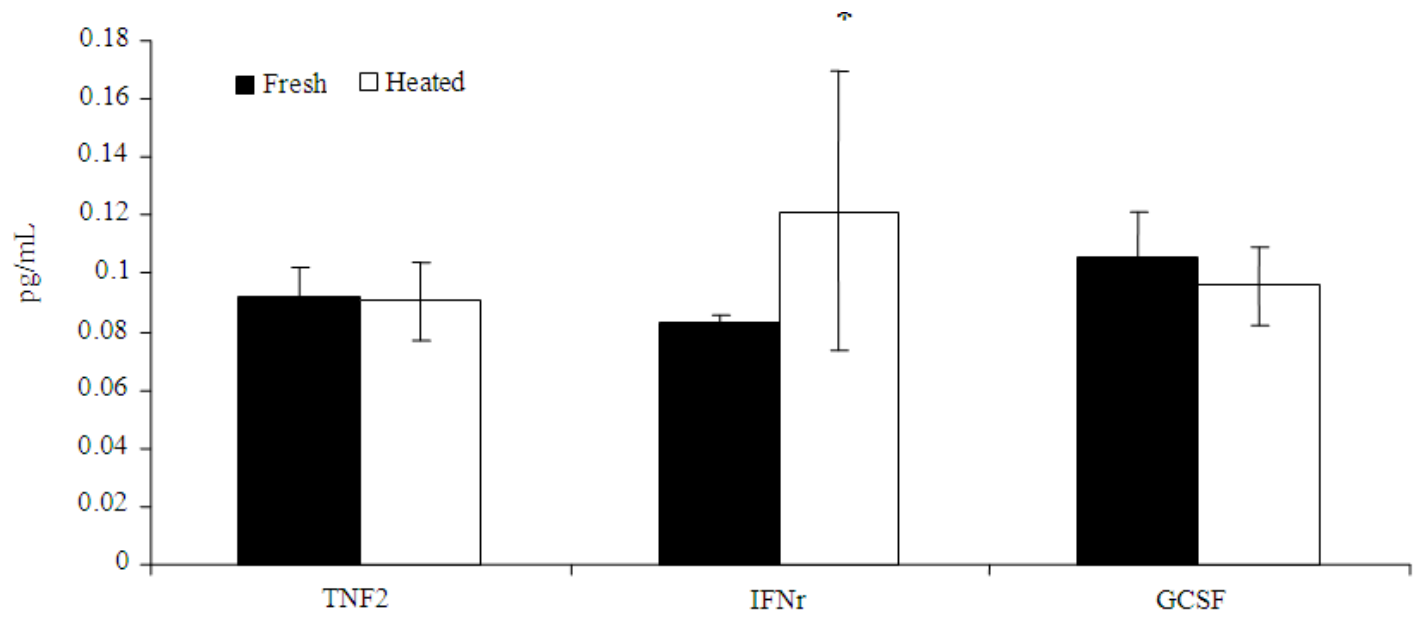

Fig. 6. Cytokine levels of bovine neutrophils exposed to heated and fresh cherokee purple polyphenolic extract. *p<0.05; Tumor necrosis factor-alpha (TNF- $\alpha$ ), interferon (IFNr) and Granulocyte - Colony Stimulating Factor (G-CSF) 


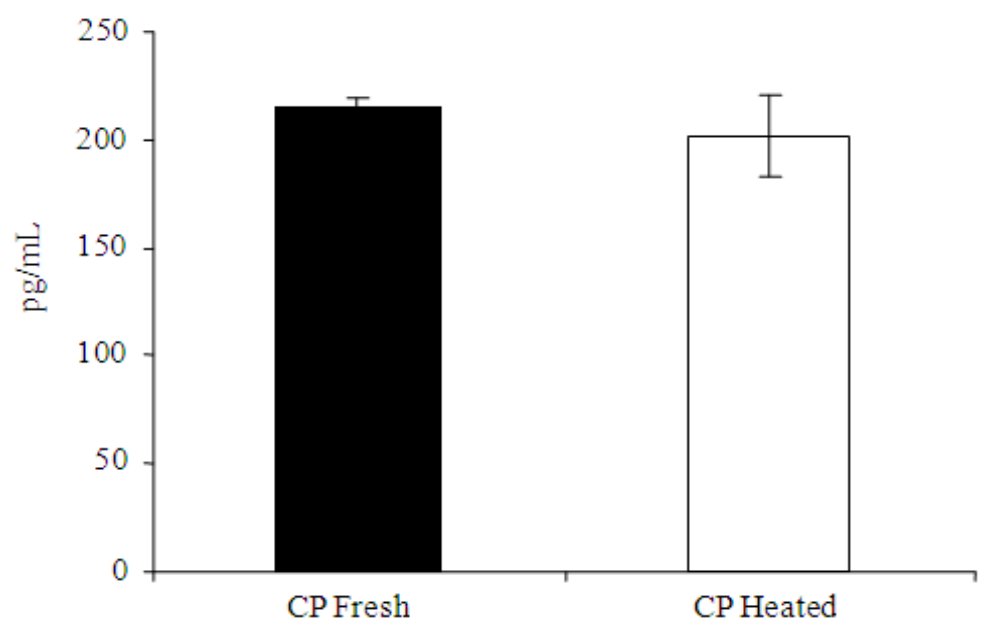

Fig. 7. Cyclooxygenase-2 levels of bovine neutrophils exposed to heated and fresh cherokee purple (CP) polyphenolic extract

\section{DISCUSSION}

The availability of bioactive compounds in tomatoes has been proposed to prevent degenerative diseases including cancers through antioxidative action and/or the modulation of several protein functions. For instance, the intake of antioxidative polyphenols (tomato) has been discussed to reduce coronary heart disease through suppression of the oxidation of low-density lipoprotein (Hertog et al., 1995; Meyer et al., 1998).

However, it is important to determine the amounts of polyphenols in tomatoes whether fresh or blanched. Several studies have reported differences in tomato when blanched and fresh samples were used. In a study by Stahl and Sies (1992) increased lycopene bioavailability was reported after cooking. High phenolic levels after blanching and heating at $100^{\circ} \mathrm{C}$ for $30 \mathrm{~min}$ has been discussed (Shen et al., 2007). In this study we found high phenolic peaks using infrared spectroscopy. An inverse observation was made when compared with that of Filin-Ciocalteu method where fresh tomato had much higher phenolic levels indicative that the methodology and sensitivity of assay could influence the observation made when determining phenolic levels in tomato and the bioavailability of active phenolics could influence the results.

The recruitment of neutrophils and pro-inflammatory compounds is linked to virtually all chronic degenerative diseases, including cardiovascular disease, cancer, osteoporosis and Alzheimer's disease. This offers evidence for the health benefits of consuming tomatoes. Our result showed that activation of fresh TP treated neutrophils with LPS, suppressed TNF- $\alpha$ and Cox-2 expressions. However, heated TP exposed cells showed significant differences in gene expressions than fresh TP.
To our knowledge, this is the first study measuring the effect of heirloom tomato extracts on levels of TNF- $\alpha$ and Cox- 2 expression in bovine neutrophils. Cell studies showed that phenolic extracts of heated tomatoes resulted in increased suppression of Cox-2 expression compared with that of fresh tomato (Shen et al., 2007). Studies in-vitro and ex-vivo have shown that the Cox-2 level in lymphocytes, neutrophils and monocytes are found inducible (Kimura et al., 2003; Capone et al., 2004; Pascual-Teresa et al., 2004). The major finding from this study was that polyphenol extracts form fresh Cherokee purple modulate expression of pro-inflammatory genes in bovine neutrophils. Further, post harvest handling through heating impacts the effect of tomato polyphenols on transcription of Cox-2 and translation of IFNr. Detection of gene expression at the level of transcription and translation of proteins from bovine neutriophils may be impacted by several factors including assay parameters such as reagent specificity, sensitivity and timing in addition to magnitude of response (Worku and Morris, 2009). Genetic variation between cows, assay sensitivity and specificity may impact gene expression studies.

The results of this study showed that in addition to nutritive values tomatoes in animal feed may modulate gene expression impacting the inflammatory response to disease. Specialty markets continue to demand heirloom tomatoes. The whole tomato and its products play protective roles in health and are associated with reduction of chronic disease. Compounds with potential health benefits in tomatoes include lycopene, flavonoids and polyphenols. Genetics, environment, cultural practices and post harvest handling and processing can impact the phyto-chemical composition of tomatoes. Open pollinated (heirloom) and specialty tomatoes varieties are gaining popularity by consumers 
for their taste, unique shapes and colors. Further they offer producers avenues for diversification of products. Most heirloom tomatoes do not have an extended shelf life and thus may require special growing techniques and attention to post-harvest handling. Oxidative stress (the production of excessive amounts of free radicals within cells) and the production of inflammatory substances are associated with chronic diseases. Extracts from NC Heirloom tomatoes have not been characterized for antioxidant content and antiinflammatory action. Such characterization may increase the economic incentive for conservation, production and marketing of such varieties in NC.

\section{CONCLUSION}

The current study showed crude polyphenol extracts of Cherokee purple tomato to modulate expression of proinflammatory genes in bovine neutrophils. Thus; potentially providing avenues to enhance innate immunity in animals and humans. Our current findings though priliminary, may potentially pave the road for further investigations on potential positive effects of North Carolina Heirloom in disease of economic importance.

\section{ACKNOWLEDGEMENT}

Funding for this study was provided by Center for Excellence in Post Harvest Technologies and the Agricultural Research Program for support of postdoctoral training and research. Special Thanks to Dr. Ofei Mante for help with FTIR and Miss Jamie Williams for editorial comments.

\section{REFERENCES}

Basu, A. and V. Imrhan, 2007. Tomatoes versus lycopene in oxidative stress and carcinogenesis: Conclusions from clinical trials. Eur. J. Clin. Nutr., 61: 295-303. PMID: 16929242

Black, P.H., 2000. Stress and the inflammatory response: A review of neurogenic inflammation. Brain Behav. Immun., 16: 622-653. PMID: 12480495

Burton-Freeman, B. and K. Reimers, 2010. Tomato consumption and health: Emerging benefits. Am. J. Lifestyle Med., 5: 182-191. DOI: 10.1177/1559827610387488

Burvenich, C., V.V. Merris, J. Mehrzad, A. Diel-Fraile and L. Duchateau, 2006. Severity of E. coli mastitis is mainly determined by cow factors. Vet. Res., 34: 521-564. PMID: 14556694
Butelli, E., L. Titta, M. Giogrio, H.P. Mock and A. Matros et al., 2008. Enrichment of tomato fruit with health-promoting anthocyanins by expression of select transcription factors. Nature Biotechnol., 26: 1301-1308. DOI: 10.1038/nbt.1506

Capone, M.L., S. Tacconelli, M.G. Sciulli, M. Grana and E. Ricciotti et al., 2004. Clinical pharmacology of platelet, monocyte and vascular cyclooxygenase inhibition by naproxen and low-dose aspirin in healthy subjects. Circulation, 109: 1468-1471. PMID: 15037526

Celis, J.E., 2006. Cell Biology: A Laboratory Handbook. 3rd Edn., Elsevier Academic, Oxford, ISBN-10: 0121647315, pp: 2141.

Carlson, G.P. and J.J. Kaneko, 1973. Isolation of leukocytes from bovine peripheral blood. Exp. Biol. Med., 142: 853-856. DOI: 10.3181/00379727-142-37131

Ellinger, S., J. Ellinger and P Stehle, 2006. Tomatoes, tomato products and lycopene in the prevention and treatment of prostate cancer: Do we have the evidence from intervention studies? Curr. Opin. Clin. Nutr. Metab., 9: 722-727. PMID: 17053426

Falik, E., 1993. Postharvest heat treatment of tomatoes to reduce rots while maintaining fruit quality. Hassadeh. 73: 972-976.

Gahler, S., K. Otto and V. Böhm, 2003. Alterations of vitamin $\mathrm{C}$, total phenolics and Alterations of vitamin $\mathrm{C}$, total phenolics and antioxidant capacity as affected by processing tomatoes to different products. J. Agric. Food Chem., 51: 7962-7968. PMID: 14690380

Grimble, R.F., 1990. Nutrition and cytokine action. Nutr. Res. Rev., 3: 193-210.

Hertog, M.G.L., D. Kromhout, C. Aravanis, H. Backburn and R. Buzina et al., 1995. Flavonoid intake and long-term risk of coronary heart disease and cancer in the seven countries study. Arch. Intern. Med., 155: 381-386. PMID: 7848021

Heuze, V., T. Gilles, B. Denis, H. Philippe and L. Francois, 2011. Tomato pomace, tomato skins and tomato seeds. Feedipedia.org and Tables Regions Chaudes. A project by INRA, CIRAD and AFZ with the support of FAO. Feedipedia-Animal Feed Resources Inform. Syst.

Hoover, M.W. and R.A. Dennison, 1957. Preliminary studies on the utilization of cull tomatoes. Proc. Fla. State Hort. Soc., 70: 211-214.

Kimura, T., M. Iwase, G. Kondo, H. Watanabe and M. Ohashi, 2003. Suppressive effect of selective cyclooxygenase- 2 inhibitor on cytokine release in human neutrophils. Int. Immun., 3: 519-1528. PMID: 12946449 
Lahti, A., M. Lahde, H. Kankaanranta and E. Moilanen, 2000. Inhibition of extracellular signal-regulated kinase suppresses endotoxin-induced nitric oxide synthesis in mouse macrophages and in human colon epithelial cells. J. Pharmacol. Exp. Ther., 294: 1188-1194. PMID: 10945876

Liang, Y.C., Y.T. Huang, S.H. Tsai, S.Y. Lin-Shiau and C.F. Chen et al., 1999. Suppression of inducible cyclooxygenase and inducible nitric oxide synthase by apigenin and related flavonoids in mouse macrophages. Carcinogenesis, 20: 1945-1952. DOI: 10.1093/carcin/20.10.1945

Lucier, G. and R.L. Dettmann, 2008. Vegetables and Melons Situation and Outlook Yearbook. 1st Edn., USDA, USA., pp: 186.

Melendez-Martinez, A.J., P.D. Fraser and P.D. Bramley, 2010. Accumulation of health promoting phytochemicals in wild relatives of tomato and their contribution to in vitro antioxidant activity. Phytochemistry, 71: 1104-1114. PMID: 20457456

Meyer, A.S., M. Heinonen and E.N. Frankel, 1998. Antioxidant interactions of catechin, cyanidin, caffeic acid, quercetin and ellagic acid on human LDL oxidation. Food Chem., 61: 71-75. DOI: 10.1016/S0308-8146(97)00100-3

Milner, S.E., N.P. Brunton, P.W. Jones, N.M. O'Brien and S.G. Collins et al., 2011. Bioactivities of glycoalkaloids and their aglycones from Solanum species. J. Agric. Food Chem., 59: 3454-3484. DOI: $10.1021 /$ jf200439q

Nagahata, H., 2004. Bovine Leukocyte Adhesion Deficiency (BLAD): A review. J. Vet. Med. Sci., 66: 1475-1482. PMID: 15644595

Pascual-Teresa, S.D., K.L. Johnston, M.S. Dupont, K.A. O'Leary and P.W. Needs et al., 2004. Quercetin metabolites downregulate cyclooxygenase-2 transcription in human lymphocytes ex vivo but not in vivo. J. Nutr., 134: 552-557. PMID: 14988445

Pfaffl, M.W., 2001. A new mathematical model for relative quantification in real-time RT-PCR. Nucleic Acids Res., 29: e45-e45. PMID: 11328886

Plummer, SM., K.A. Hill, M.F. Festing, W.P. Steward and A.J. Gescher et al., 2001. Clinical development of leukocyte cyclooxygenase 2 activity as a systemic biomarker for cancer chemopreventive agents. Cancer Epidemiol. Biomarkers Prev., 10: 12951299. PMID: 11751448

Rafi, M.M., P.N. Yadav and M. Reyes, 2007. Lycopene inhibits LPS-induced proinflammatory mediator inducible nitric oxide synthase in mouse macrophage cells. J. Food Sci., 72: S069-S074. PMID: 17995901
Riso, P., F. Visioli, S. Grande, S. Guarnieri and C. Gardana, 2006. Effect of a tomato-based drink on markers of inflammation, immunomodulation and oxidative stress. J. Agric. Food Chem., 54: 25632566. PMID: 16569044

Roth, J.A., Kaeberle and M.L. Karberle, 1981. Effects of in vivo dexamethasone administration on in vitro bovine polymorphonuclear leukocyte function. Infect. Immun., 33: 434-441.

Sautebin, L., 2000. Prostaglandins and nitric oxide as molecular targets for anti-inflammatory therapy. Fitoterapia, 71: S48-S57. PMID: 10930713

Schmitz, S., M.W. Pfaffl, H.H.D. Meyer and R.M. Bruckmaier, 2004. Short-term changes of mRNA expression of various inflammatory factors and milk proteins in mammary tissue during LPS-induced mastitis. Domestic An. Endocrinol., 26: 111-126. PMID: 14757184

Schwalm, O.W., J. Lasmani and N.C. Jain, 1976. Conversion of chronic staphylococcal mastitis to acute gangrenous mastitis after neutropenia in blood and bone marrow produced by an equine anti-bovine leukocyte serum. Am. J. Vet. Res., 37: 885-890. PMID: 949115

Shen, Y.C., S.L. Chen and C.K. Wang, 2007. Contribution of tomato phenolics to antioxidation and down-regulation of blood lipids. J. Agric. Food Chem., 55: 6475-6481. PMID: 17629300

Silva, E., M. Gaivao, S. Leitao, A. Amaro and L.L. Costa et al., 2008. Blood COX-2 and PGES gene transcription during the peripartum period of dairy cows with normal puerperium or with uterine infection. Domest. Anim. Endocrinol., 35: 314-323. PMID: 18692980

Stahl, W. and H. Sies, 1992. Uptake of lycopene and its geometrical isomers is greater from heat-processed than from unprocessed tomato juice in humans. J. Nutr., 122: 2161-2166. PMID: 1432255

Tkalcevic, J., M. Novelli, M. Phylacrtieds, J.P. Iredale and A.W. Segal et al., 2000. Impaired immunity and enhanced resistance to endotoxin in the absence of neutrophil elastase and cathepsin G. Immunity, 12: 201-210. PMID: 10714686

Ventura, M.R., M.C. Pieltain, J.I.R. Castanon, 2009. Evaluation of tomato crop by-products as feed for goats. Ani. Feed Sci. Technol., 154: 271-275.

Waterman, J. and M. Worku, 2001. Bovine PMN release the COX-2 protein when stimulated with bacterial lipopolysaccharide. ASAS/ADSA Anim. Health Abstract.

Worku, M. and A. Morris, 2009. Binding of different forms of lipopolysaccharide and gene expression in bovine blood neutrophils. J. Dairy Sci., 92: 31853193. PMID: 19528595 